1 Fundação Oswaldo Cruz (Fiocruz), Escola Nacional de Saúde Pública Sergio Arouca (Ensp) - Rio de Janeiro (RJ), Brasil.

simoneccohen@gmail.com

\section{Habitação saudável e biossegurança: estratégias de análise dos fatores de risco em ambientes construídos}

\author{
Healthy housing and biosafety: strategies of analysis of the risk \\ factors present in built environments \\ Simone Cynamon Cohen', Telma Abdalla de Oliveira Cardoso', Marli Brito Moreira de \\ Albuquerque Navarro', Débora Cynamon Kligerman' ${ }^{1}$
}

DOI: 10.1590/0103-1104201912317

RESUMO Este artigo objetivou discutir as estratégias proporcionadas pelos campos reflexivos e das ações propostas pelos estudos sobre habitação saudável e biossegurança, observando-as enquanto ferramentas que podem ser aplicáveis em diagnósticos de ambientes construídos para análise dos fatores de risco, sobre aspectos correlatos à qualidade ambiental. Como metodologia, optou-se, inicialmente, pela pesquisa exploratória para discutir a habitação saudável e a biossegurança como suportes analíticos para apontar fatores de risco existentes em ambientes construídos, tendo como base as pesquisas de campo realizadas em assentamentos humanos irregulares. Em seguida, utilizou-se a pesquisa bibliográfica para o alcance do aprofundamento teórico-conceitual implícito nas formulações de estratégias pertinentes aos dois campos. Como resultados, observaram-se as interfaces entre ambos e verificou-se que se complementam e podem contribuir para a realização de um checklist em ambientes construídos, identificando fatores internos e externos, no sentido de promover, sobretudo, a segurança e a qualidade. Para tornar mais clara a compreensão dos dados analisados, identificaram-se quais eram as condições fundamentais para ambientes construídos saudáveis e seguros. Conclusivamente, destacou-se a relevância das ações transformadoras capazes de orientar um checklist em ambientes construídos.

PALAVRAS-CHAVE Habitação. Saúde ambiental. Contenção de riscos biológicos. Risco. Gestão de qualidade.

\begin{abstract}
This article aims to discuss the strategies offered by reflective fields and actions proposed by the studies on healthy housing and biosafety, noting them as tools that can be applied in diagnostics of environments built for the analysis of risk factors, on aspects related to environmental quality. As a methodology, we opted for the first exploratory research to discuss the healthy housing and biosecurity as analytical brackets to point out existing risk factors in built environments, based on the field research carried out in irregular human settlements. Then, bibliographical research was used to achieve the theoretical-conceptual deepening implied in the formulations of strategies pertinent to the two fields. As results were observed between both interfaces and found to complement each other and can contribute to the realization of a checklist in built environments, identifying internal and external factors, in order to promote safety and quality. To clarify the understanding of the data analyzed, we identified which were the fundamental conditions for healthy and safe built environments. Conclusively, the relevance of transformative actions that are capable of guiding a checklist in built environments was highlighted.
\end{abstract}

KEYWORDS Housing. Environmental health. Containment of biohazards. Risk. Quality management. 


\section{Introdução}

Neste artigo, são apresentadas as estratégias formuladas pelos campos da habitação saudável e da biossegurança como ferramentas e suportes analíticos aplicáveis aos projetos de ambientes construídos.

A biossegurança trata-se de um conjunto de ações de prevenção, controle, redução e eliminação de riscos, que possa impactar na saúde humana, animal e do meio ambiente.

A estratégia de habitação saudável avalia os riscos existentes no ambiente interno e externo e que podem comprometer a saúde humana e ambiental. Portanto, ambas as estratégias visam à garantia de ambientes seguros, saudáveis e com qualidade.

A escolha dos campos da habitação saudável e da biossegurança se deve ao fato de terem em comum a necessidade de fazer um checklist para o monitoramento dos fatores de risco internos e externos ao ambiente construído que impactam na saúde humana e ambiental, para a tomada de medidas de intervenção necessárias de curto, médio e longo prazo, segundo seu nível de gravidade.

Identificam-se, a princípio, os fatores de risco existentes nos recintos para que se possa prosseguir no processo de qualificação ambiental dos espaços para sua preservação e proteção no intuito de se tornarem mais saudáveis e seguros.

Dessa forma, levantam-se dados pertinentes ao ambiente físico, passo a passo, de forma participativa, essencial para o processo de planejamento do ambiente a ser construído, uma vez que preenche de significados do espaço físico, aproximando-o das necessidades reais, tornando, assim, o projeto mais sustentável.

Este artigo, portanto, objetiva discutir as estratégias proporcionadas pelos campos reflexivos e das ações propostas pelos estudos sobre habitação saudável e biossegurança, como suportes analíticos de identificação dos fatores de risco existentes em ambientes construídos; no intuito de subsidiar os profissionais que venham a participar no processo de elaboração do projeto arquitetônico, demonstrando a importância de sua aplicabilidade aos diagnósticos de ambientes construídos para análise dos fatores de risco, manifestos ou latentes, aspectos correlatos à qualidade ambiental e segurança.

Como metodologia, optou-se pela pesquisa exploratória e bibliográfica, por meio da qual se buscou o aprofundamento teórico-conceitual implícito nas formulações de estratégias pertinentes à habitação saudável e à biossegurança, tais como: ambiente e entorno saudável; biossegurança; risco; qualidade e saúde. Desse modo, para a configuração do artigo, inicialmente, embrenhou-se pelo tema dos ambientes construídos e da habitação saudável. Depois, adentrou-se pelo campo da biossegurança e, em seguida, desenhou-se a interface entre a habitação saudável e a biossegurança como estratégia de análise dos ambientes construídos.

\section{Ambientes construídos e habitação saudável}

No processo de formulação, implementação e avaliação de políticas, programas e projetos habitacionais de interesse social, como estratégias de promoção da saúde em assentamentos humanos informais, deve-se partir da reflexão e do debate teórico-conceitual sobre o que é a metodologia de habitação saudável e como, por intermédio dessa iniciativa, pode-se atingir padrões de habitabilidade aceitáveis com qualidade e segurança. Assim, por meio de cenários reais e do compromisso dos profissionais na articulação e integração com prioridades comunitárias e de movimentos sociais organizados, ter-se-ia efetividade da promoção da saúde em iniciativas habitacionais $\mathbf{1}^{\mathbf{1}} \mathbf{2}$. Portanto, é fundamental pensar na relação entre habitação, saúde e ambiente, no sentido de promover políticas públicas saudáveis e ambientes favoráveis à saúde, para ter um incremento gradativo da situação de vida da população; como também, para o entendimento da relação entre a habitação e a saúde, é fundamental a 
compreensão da moradia como um determinante social da saúde. Dessa forma, é essencial o aprofundamento de habitação e saúde como política pública saudável.

Na 'Declaração de Adelaide'2, as políticas públicas saudáveis aparecem como instrumentos de equidade; e pelos compromissos com o impacto de tais políticas sobre a saúde da população e por seu intermédio, poder-se-ia buscar, equacionar a capacidade do Estado em responder aos anseios populacionais e auxiliar no enfrentamento do quadro de exclusão social.

Na 'Declaração de Sundsvall'3, fez-se o entendimento de ambientes favoráveis à saúde incorporando as dimensões física (água, esgoto, resíduos sólidos domésticos e industriais, drenagem urbana, controle de vetores, proteções da atmosfera, solo, rios, lagoas e oceanos), social, política, econômica e cultural. Por conseguinte, para o espaço construído ser considerado um ambiente favorável à saúde, precisaria da identificação da interdependência com outros setores no processo de conservação e proteção ambiental. Nesse sentido, necessitaria, assim, da evolução do conhecimento sobre a saúde, e sua contribuição, com a abordagem da habitação saudável, transformando a habitação em espaço de manutenção da saúde de seus moradores.

Dessa forma, a habitação é considerada por um dos espaços em que os indivíduos convivem ao longo de suas existências, assim como as escolas, o lugar de trabalho, o hospital, a comunidade, o bairro, a cidade, o país, entre outros. Não é somente o espaço físico, mas também o sociocultural, técnico-sanitário e psíquico que deve ter qualidade para ser habitável. Os requisitos fundamentais para ter uma habitação saudável, com promoção e proteção da saúde humana, seriam: relação de vizinhança equilibrada, funcionalidade de cada espaço interno, flexibilidade do espaço, infraestrutura de serviços e equipamentos básicos, racionalidade das soluções do espaço, qualidade e durabilidade das construções, segurança (entendida como fator físico, social e sanitário), habitabilidade urbana e da unidade habitacional, em que a configuração final de uma habitação seria traduzida pela forma espacial de cada cômodo e pela acessibilidade do espaço ${ }^{4-6}$.

\section{Biossegurança}

Entendida como área do saber, a biossegurança possui um alicerce marcado pela construção de sentidos e significados complexos, associados aos processos tecnológicos e científicos, que oferece suporte analítico para a gestão dos fatores multicausais atrelados aos riscos existentes em ambientes construídos. Os seus princípios começam a ser incorporados modificando concepções espaciais, de materiais de acabamento, mobiliários, tratamento, renovação do ar e diferenciais de pressão, para minimizar os eventuais riscos ambientais que possam estar presentes, exigindo um esforço conjunto por parte dos profissionais envolvidos, de modo a estabelecer, no projeto arquitetônico, padrões e normas que assegurem a qualidade ambiental, com o cumprimento das condições de segurança necessárias ${ }^{7}$. Porém, a dimensão inovadora da biossegurança está ainda restrita às soluções projetuais da estrutura física voltadas para áreas laborais. No entanto, as muitas variáveis que podem revelar a relação causa e efeito entre as condições ambientais e os tipos de agressão à saúde de seus ocupantes e ao meio ambiente passam a ser questionadas em outras áreas como a da habitação.

O relatório da Organização Mundial da Saúde (OMS) ${ }^{\mathbf{8}}$ a respeito da relação entre saúde e moradia aponta para seis princípios que expressam e reforçam a importância das relações entre a habitação saudável e a biossegurança como estratégia para a análise dos riscos ambientais; unindo os conhecimentos de saneamento dirigidos à prevenção e ao controle dos riscos biológicos, químicos, sanitários, físicos e socioambientais presentes no microespaço da habitação e no peridomicílio ${ }^{2,5,9}$. Apesar disso, a biossegurança no Brasil tem tido uma trajetória também relacionada com as 
preocupações sociais e ambientais destinadas a conhecer e a controlar os riscos que o trabalho científico pode oferecer ao ambiente e à vida ${ }^{10}$.

O primeiro princípio da OMS está relacionado com a proteção contra a exposição aos agentes etiológicos e vetores de doenças infectocontagiosas. Ele se refere ao espaço adequado para o número de habitantes, ao suprimento adequado de água potável, ao sistema de esgotamento sanitário e ao sistema de descarte de resíduos sólidos, para redução da transmissão de doenças, principalmente as gastrointestinais e de doenças como a Dengue, a Chikungunya e a Zika, além de reduzir a proliferação de insetos e roedores ${ }^{9}$. Ressalta-se que o design, as características estruturais e de preservação e de manutenção das estruturas habitacionais podem afetar a proteção contra as doenças. Pisos de terra favorecem a criação e a nidificação de vetores de doenças. A falta de ventilação adequada, dada pela colocação de portas e janelas, é motivo de preocupação, porque também pode afetar a proteção contra doenças transmissíveis. A superlotação, particularmente em associação à pobreza, e instalações inadequadas estão relacionadas com a transmissão de tuberculose, pneumonias, bronquites e infecções gastrointestinais.

O segundo princípio determina que as habitações forneçam proteção contra danos evitáveis, envenenamentos, temperaturas extremas, riscos de desastres naturais, ruídos e outras exposições que possam contribuir para doenças crônicas 9 .

Especial atenção deve ser dada aos aspectos estruturais, como, por exemplo, a localização; de modo a prevenir riscos, tais como: ruídos, temperaturas extremas, poluição, inundações e deslizamentos de terra. Os mobiliários, os materiais utilizados na construção, assim como os acabamentos são itens importantes para a manutenção de ambientes seguros, confortáveis, ventilados, livres de substâncias químicas perigosas e de insetos e roedores.

O terceiro princípio está relacionado com a saúde mental, ressaltando a importância da habitação adequada ao desenvolvimento social e psicológico dos indivíduos. A habitação deve minimizar ao máximo o estresse. É o entendimento de que a habitação é um refúgio seguro, sem fatores estressantes como ruído e calor, equipado e mobiliado, a fim de fornecer um ambiente que permita o estabelecimento de interações pessoais e sociais, além de conforto, privacidade, aconchego e segurança aos seus habitantes. Quando a habitação fornece essas funções, a saúde mental é reforçada9.

De acordo com o quarto princípio, os ambientes habitacionais adequados devem fornecer acesso aos locais de trabalho e aos serviços sociais necessários para a promoção da saúde e da segurança9.

O quinto princípio destaca o uso adequado da habitação para a promoção da saúde. É necessário que a estrutura habitacional seja mantida para que possa atuar na defesa contra os riscos. Da mesma forma, nenhum planejamento do uso da terra pode garantir as qualidades salubres de um bairro se seus habitantes contribuírem de forma negligente para a preservação ambiental, deixando de tomar medidas contra agressões ambientais que possam estar presentes ${ }^{9}$.

O último princípio está relacionado com a proteção das populações especiais. As habitações devem minimizar os riscos para a saúde desses grupos, incluindo mulheres e crianças, refugiados, imigrantes, idosos, portadores de necessidades especiais e doentes crônicos.

\section{Habitação saudável e biossegurança como estratégias de análise dos espaços construídos}

Dentro do espaço residencial, observa-se a existência de diversos fatores de risco. Os riscos físicos na habitação (radiação, ventilação, ruído, vibração, iluminação, insolação) se constituem de fenômenos qualificados pelos tipos de energia em que eles se manifestam, ou seja, mecânica, termodinâmica, sonora, 
elétrica e nuclear. Os riscos químicos têm por objetivo categorizar os tipos de efeitos e danos dos produtos químicos mais significativos e os seus processos de contaminação ambiental. Os riscos ergonômicos dizem respeito aos elementos posturais inadequados, monotonia, repetitividade, esforços físicos intensos, levantamento e transporte de pesos. Riscos psicossociais estão intrinsicamente relacionados com o contexto social no qual a moradia está inserida e com os fatores externos que predominam, como violência, que provocam estresse físico ou psíquico. Os riscos biológicos estão relacionados com os agentes biológicos presentes no ambiente, como: fungo, bactérias, vírus, vetores, entre outros. Há ainda os fatores de risco de acidentes, como o uso de ferramentas defeituosas, sobrecarga elétrica, probabilidade de incêndio e arranjos físicos inadequados. Riscos sanitários são relativos ao abastecimento de água da rede pública chegando ao interior da residência; a rede de esgotamento sanitário saindo da moradia e indo para um coletor público; coleta de resíduo sólido; existência de rede de drenagem pluvial e bueiros aos longos das vias de circulação próximas às residências. Riscos socioeconômicos estão intimamente ligados ao poder aquisitivo familiar e às questões de renda, emprego, nível de escolaridade, entre outros ${ }^{2,7}$. Assim, o espaço físico deve compatibilizar os elementos relativos à construção com os métodos que buscam a manutenção da qualidade ambiental, objetivando a redução ou a eliminação de haver a ocorrência de efeitos adversos dos agentes causais de desequilíbrios ambientais ou de risco que possam causar impactos à saúde ou ao ambiente. Dessa forma, uma análise dirigida para o controle dos riscos ambientais deve ser primordial na construção das habitações, direcionada ao planejamento que promova espaços mais seguros e ambientalmente sustentáveis, equilibrando exigências projetuais e aspectos de biossegurança ${ }^{11}$.

Nas fases de planejamento e programação arquitetônica, os aspectos construtivos de localização, tipologia, estrutura, redes prediais e outros sistemas devem estar relacionados com as necessidades espaciais de flexibilidade, segurança, contenção, manutenção, cuidados, vigilância, qualidade ambiental e monitoramento.

É importante salientar que as estratégias da habitação saudável e da biossegurança estão relacionadas com o momento do planejamento, e do projeto, levantamento das condições de segurança relativas à escolha da localização da edificação, dimensionamento físico do ambiente construído e aos critérios de sua organização espacial e funcional. Para a elaboração de projetos de construção, há a necessidade da observância dos requisitos estabelecidos pelas legislações federais e de outras disposições que, com relação à matéria, estejam incluídas em regulamentos sanitários e ambientais dos estados e em códigos de obras municipais ou onde se situem as respectivas edificações. Envolve os seguintes critérios ${ }^{5,7,11-13}$ :

\section{Localização da edificação}

Na escolha da localização, deve-se observar a geomorfologia do terreno, avaliando os riscos de deslizamentos, inundações, erosões; as fontes de ruído e vibrações; incidência solar; fontes de poluições; infraestrutura disponível, como redes de água, elétrica, de esgoto etc.

Ela está também muito relacionada com as interações com construções existentes e com a integração social, incorporando fatores de equilíbrio com a vizinhança estabelecendo limites de cada morador; de acessibilidade, independentemente da faixa etária e do estado físico do morador; de mobilidade urbana onde os habitantes tenham acesso aos meios de transportes existentes, redes de convivência e sobrevivência, como supermercados, restaurantes, bares, lojas de roupas, escolas e creches, igrejas, áreas de esporte e lazer, redes de assistência à saúde e outros serviços.

\section{Dimensionamento}

O dimensionamento está diretamente ligado às necessidades espaciais para atender aos 
requisitos mínimos para a habitação do indivíduo, ou seja, a forma espacial de cada cômodo e seu uso. Deve considerar a funcionalidade de cada espaço com as necessidades humanas (cozinhar, estudar, repousar etc.), considerando mobiliário, pessoal e espaço de circulação; além dos requisitos ambientais de flexibilidade, devido à possibilidade de ampliação e de transformação para atendimento a outras demandas futuras. É, portanto, uma tarefa difícil.

\section{Organização funcional}

A habitação é evidentemente um ambiente diferenciado dos espaços laborais, que exige elementos de construção e equipamentos adequados aos seus moradores, independentemente da faixa etária e do estado físico, e características de flexibilidade e comunicação, de modo a promover interações sociais, por meio de ambientes agradáveis ao convívio. Cada ambiente construído (habitação, escola, hospitais, indústrias, comercio, praças públicas) é incorporado por espaços segundo suas funções e sua organização.

\section{Características arquitetônicas}

Carvalho e Tavares ${ }^{\mathbf{1 4}}$ demonstram que a utilização de um desenho modular da edificação racionaliza o processo projectual, já que estabelece uma limitação às medidas aplicáveis aos componentes e ao projeto, assegurando, ao mesmo tempo, flexibilidade de combinação de medidas e facilidade de produção; possibilita o emprego de componentes da construção com poucas adaptações locais e sem a necessidade de modificações do projeto para a obra, evitando gastos e perda de tempo; uso múltiplo dos espaços projetados e facilitam posteriores reformas, ampliações, manutenção e adaptações em geral.

O uso do desenho modular é mais frequente em obras que requerem um método construtivo rápido e racionalizado, como é o caso dos conjuntos habitacionais e de escolas.

O módulo básico possui dimensões de comprimento e largura preestabelecidas, que podem variar devido aos arranjos padrões necessários para os equipamentos, as circulações e as outras áreas da edificação.

No estabelecimento das dimensões do módulo básico, deve-se observar a divisibilidade do módulo em unidades menores; o dimensionamento das circulações internas, do mobiliário e dos equipamentos; a localização das redes prediais de energia elétrica, água, gases e demais sistemas de engenharia; as características dos materiais construtivos e de acabamento propostos ou existentes e outros elementos que possam interferir no espaço habitacional.

\section{Características construtivas e ambientais}

As características construtivas da habitação e dos materiais utilizados devem prover condições adequadas de salubridade aos seus usuários, dificultando o acesso de insetos e roedores, e propiciando níveis aceitáveis de material particulado em suspensão, de construções e reformas; gases tóxicos oriundos do tráfego intenso de veículos e outras poluições ambientais provenientes dos ambientes externos; aerossóis e poeiras presentes nas características do mobiliário e dos equipamentos; agentes infecciosos; e outros.

A observação dos critérios relacionados com as características ambientais da habitação é importante a fim de dotar de conforto ambiental, ou seja, adequando o ambiente construído ao uso do homem, respeitando tanto as condições térmicas, de ventilação e/ou de incidência solar como os aspectos acústicos e visuais.

Essas caraterísticas dizem respeito ao modelo construtivo e de acabamento, tais como: fundação (alicerce); lajes, vigas e pilares; telhado; portas e janelas; materiais empregados nas paredes, piso e teto; e eixos de circulação (escadas, corredores, rampas e elevadores).

Coberturas, fachadas e janelas devem propiciar estanqueidade às poeiras e aerodispersoides, de forma que sua concentração não 
exceda aquela verificada no ambiente externo.

O telhado e as coberturas não podem apresentar peças que se desprendam ou se desloquem sob ação do próprio peso ou do vento e de outras cargas acidentais. As coberturas que sejam constituídas por peças metálicas devem ser aterradas, a fim de propiciar a condução das descargas e a dissipação de cargas eletrostáticas eventualmente acumuladas nas telhas pelo atrito com o vento.

As paredes, pisos e tetos devem ser executados com materiais que não favoreçam a retenção de umidade e a proliferação de agentes biológicos, como os fungos.

Os pisos não podem apresentar irregularidades que possam provocar quedas nos usuários. As juntas não devem exceder $4 \mathrm{~mm}$, excetuando-se o caso de juntas de movimentação em ambientes externos. Devem possuir a maior planicidade possível, apresentando quedas suaves em direção aos ralos ou às canaletas de drenagem. Não podem propiciar empoçamento de água que favoreça o desenvolvimento de larvas de mosquitos. Nas áreas dos chuveiros ou em pisos externos, o caimento deve ter no máximo $2 \%$, e $1 \%$ nas demais áreas. Caso haja desníveis superiores a $5 \mathrm{~mm}$, deve haver um sistema de sinalização que garanta a visibilidade deste desnível, como, por exemplo, mudanças de cor e de faixas de sinalização ${ }^{15}$.

Os requisitos de conforto térmico e acústico dos usuários das edificações devem ser observados.

a) Conforto térmico - é um fator que repercute no conforto das pessoas, para o desempenho de suas atividades normais na habitação.

A sensação de conforto térmico depende muito das condições de ventilação dos ambientes, com grande influência do posicionamento e das dimensões das aberturas de janelas, porém, também está diretamente relacionada com o desempenho térmico da edificação, além de interferir no consumo de energia, por uso de sistemas de ventilação ou climatização elétricos.

O desempenho térmico depende de diversas características: localização da obra (topografia, temperatura e umidade do ar, radiação solar, direção e velocidade do vento etc.) e da edificação (propriedades térmicas dos materiais constituintes das fachadas e das coberturas, número de pavimentos, dimensões dos cômodos, pé-direito, orientação das fachadas, aberturas e tipo de portas e janelas, entre outros).

O grau de absorbância à radiação solar das superfícies expostas às condições climáticas pode ser determinado pela escolha da cor e pelas características das superfícies externas da cobertura e das paredes expostas, previstas no projeto.

As dimensões das aberturas de portas e janelas devem favorecer a incidência de raios solares no ambiente interno da casa, a ventilação e a renovação de ar dos ambientes. Além disso, o distanciamento apropriado entre edificações, e destas a taludes, muros e outros obstáculos, é essencial para garantir condições adequadas de ventilação e de iluminação natural.

A Associação Brasileiras de Normas Técnicas $(\mathrm{ABNT})^{\mathbf{1 6}}$ possui uma Norma, NBR 15575-1, estabelecendo uma taxa de ventilação no verão de cinco renovações do volume de ar do ambiente por hora $(5,0 \mathrm{ren} / \mathrm{h}$ - janela totalmente aberta) com janelas sem sombreamento; ou uma proteção na janela (persiana, cortina, ou similar) que promova a proteção de, pelo menos, $50 \%$ da radiação solar, em conjunto com uma taxa de uma renovação do volume de ar do ambiente por hora (1,0 ren/h).

b) Conforto acústico - é essencial para alcançar o bem-estar físico e psíquico dos usuários de uma edificação. É um fator que pode causar a diminuição da concentração e dos índices de produtividade e o aumento da pressão arterial e irritação. Está relacionado com ruídos externos (vizinhos, rua, carros) e internos (de certos cômodos entrando em conflito com outros). A Norma Brasileira da ABNT (NBR 10152) e a Norma Regulamentadora do Ministério do Trabalho e Emprego (NR17) estabelecem parâmetros para o conforto acústico de diversos tipos de ambientes: por exemplo, em atividades que exijam concentração, o nível ideal é abaixo de 45 decibéis (dB). O máximo 
de ruído aceitável para efeito do conforto acústico é de até $65 \mathrm{~dB}$; acima disso, pode haver efeitos adversos e até mesmo surdez nos habitantes ${ }^{17,18}$.

As características do ambiente construído, interior e exterior, são responsáveis pela qualidade acústica do espaço resultante. Fatores como forma, dimensão, volumetria, revestimento e material de vedação determinarão o som percebido pelo indivíduo.

Inicialmente, as fontes de ruído devem ser identificadas, pois elas irão direcionar as medidas de mitigação a serem tomadas. Existem ruídos de fontes externas à edificação (tráfego de veículos, indústrias, estádios esportivos, entre outros) e fontes internas (máquinas, equipamentos, áreas recreativas, entre outros).

Os materiais constantemente usados no exterior das edificações, tais como: concreto, cerâmica, pedras e asfalto; não têm coeficiente de absorção sonora bom. A presença de plantas tem um efeito significativo na ambiência sonora dos espaços ao ar livre, a partir da absorção, difusão e do mascaramento dos ruídos.

A setorização dos espaços internos da habitação é uma medida que auxilia no controle dos ruídos. Nas paredes internas da fachada voltada para a via de tráfego, localizam-se os espaços menos sensíveis (acessos, circulações, escadas); e para os ambientes sensíveis ao ruído (quartos, escritórios), reservam-se as fachadas protegidas. Áreas de serviço e cozinhas devem ser ambientes afastados dos quartos, caso não seja possível, evitar a passagem de tubulações de água e esgoto pela parede divisória.

A espessura da parede é também um determinante de diminuição de ruídos. Uma parede de alvenaria de tijolos cerâmicos (espessura média de $15 \mathrm{~cm}$ ) isola cerca de $35 \mathrm{~dB}$; e uma laje de concreto, cerca de $45 \mathrm{~dB}$. Isso também pode ser feito por meio da utilização de paredes compostas, ou seja, o uso de painel rígido sobre material absorvente (tratamento acústico), o que irá aumentar o custo do projeto.

A presença de frestas nas coberturas e nas fachadas altera substancialmente o desempenho acústico, sendo que pequenas frestas podem reduzir em mais de $30 \%$ o isolamento acústico.

As esquadrias são um dos pontos fracos da fachada por serem, usualmente, fabricadas em materiais leves, por quase sempre possuírem elementos vazados (venezianas, grelhas) e pela dificuldade de rejuntar as frestas entre a alvenaria e o caixilho e entre este e as folhas móveis. Os modelos de esquadrias de PVC, com vidro duplo, reduzem a passagem de vibração.

\section{Infraestrutura}

As habitações devem ser dotadas de instalações hidráulicas, sanitárias, elétricas e eletrônicas e de distribuição de gás natural. É fundamental ter um caderno técnico que contemple todas as informações sobre as instalações.

a) Instalações hidráulicas e sanitárias compreendem os sistemas prediais de coleta de esgoto, suprimento de água fria e quente, coleta de águas pluviais, armazenamento e coleta de resíduos sólidos. Para cada um desses sistemas, há uma série de normatizações que regulam tanto a concepção dos projetos quanto as especificações de materiais, aparelhos e procedimentos executivos. Elas são definidas em projetos segundo padrões de segurança, obedecendo às normas técnicas nacionais para facilitar a segurança, o desempenho, a economia, a operação e a manutenção do sistema, bem como a flexibilidade em modificações futuras. No projeto, deverá haver um memorial descritivo com objetivo de orientar e complementar o projeto específico, para o melhor entendimento e compreensão de como serão projetadas as instalações. A escolha dos materiais e equipamentos, suas marcas, modelos e tipos relacionam-se com as especificidades técnicas e não poderão sofrer alterações, sem justificativa prévia dos critérios de modificação, pois possuem características e normas construtivas, normas de fabricação, testes de operação e de desempenho.

As instalações hidrossanitárias devem cumprir as normas da ABNT: NBR 10844: 
'Instalações prediais de águas pluviais'; NBR 8160: 'Sistemas prediais de esgotamento sanitário, projeto e execução’; NBR 5626: 'Instalações prediais de água fria'; NBR 7198: 'Projeto e execução de instalações prediais de água quente'; e NBR 6493: 'Emprego de cores para identificação de tubulações e cores'.

b) Instalações elétricas e eletrônicas - o sistema elétrico deve ser projetado para qualquer ambiente construído, com detalhamentos a respeito da disposição dos condutores e equipamentos elétricos, de forma a ter maior segurança, confiabilidade e qualidade. Desse modo, um sistema elétrico, segundo McPartland et al. ${ }^{19}$, deverá ser dividido em três etapas básicas: 1) seleção dos conceitos básicos de instalação elétrica e configurações que irão proporcionar o fornecimento de energia elétrica, com as características desejadas a cada um dos pontos de utilização; 2) identificação dos circuitos planejados com condutores, aparelhos e acessórios, escolhendo os respectivos tipos, tamanhos, modelos, características, valores nominais e outras especificações necessárias; e 3) projeção do sistema elétrico global, mostrando as localizações dos equipamentos, os respectivos detalhes de montagem, percurso de eletrodutos, as ligações com as linhas principais de alimentação e quaisquer outros elementos que requeiram atenção especial. É fundamental considerar aspectos de flexibilidade; acessibilidade; confiabilidade e segurança ${ }^{19}$.

c) Instalações de distribuição de gás natural - o gás natural é uma mistura de hidrocarbonetos leves, como o metano que permanece no estado gasoso à temperatura ambiente e pressão atmosférica. As instalações de gás natural devem cumprir a normas da ABNT NBR 13933: 'Instalações internas de Gás Natural (GN): projeto e execução' - que se aplica às edificações e construções em geral, em execução ou sujeitas à reforma ou reconstrução, ou ainda àquelas submetidas a pequenas reformas ou reparos. É empregada nas instalações de Gases Liquefeitos de Petróleo
(GLP) e nas edificações nas quais a utilização de gás combustível se destina a finalidades industriais, que, por sua vez, possui outras normas específicas às peculiaridades de cada instalação.

\section{Considerações finais}

Com a articulação entre biossegurança e habitação saudável, foi possível identificar que são estratégias complementares e que juntas contribuem para uma visão mais holística do espaço construído e colaboram para o aumento da qualidade da habitabilidade e da segurança de uma edificação; que são fatores da salubridade, minimizando os riscos internos e externos.

Nesse sentido, o ambiente, a habitação e a saúde não devem ser tratados como independentes, pois requerem visões transdisciplinares, que não considerem somente os danos físico-sanitários, geográficos, mas também os fatores socioculturais, econômicos, políticos, organizacionais relativos ao desenvolvimento humano saudável e seguro.

A compreensão da interface entre habitação saudável e biossegurança é essencial para embasar políticas públicas saudáveis e promover ambientes favoráveis à saúde, que priorizem como objeto de estudo a análise dos riscos, no sentido da construção de ambientes mais seguros para a vida e que valorizem a qualidade ambiental e o bem-estar.

\section{Colaboradores}

Cohen SC (0000-0001-6228-6583)*, Cardoso TAO (0000-0002-5430-7273)*, Navarro MBMA (0000-0003-4408-574X)* e Kligerman DC (0000-0002-7455-7931)* contribuíram igualmente para a concepção, levantamento de dados, elaboração do rascunho e da redação, revisão crítica do conteúdo e aprovação da versão final do manuscrito. 


\section{Referências}

1. Cohen SC, Bodstein R, Kligerman DC, et al. Habitação saudável e ambientes favoráveis à saúde como estratégia de promoção da saúde. Ciênc. Saúde Colet. 2007; 12(1):191-98.

2. Adelaide Recommendations on Health Public Policy. Second International Conference on Health Promotion, Adelaide, Australia, 5-9 abr 1988. [acesso em 2018 dez 8]. Disponível em: https://www.who.int/healthpromotion/conferences/previous/adelaide/en/.

3. Declaração de Sundsvall. Promoção da saúde e ambientes favoráveis à saúde. $3^{\text {a }}$ Conferência Internacional sobre Promoção da Saúde. Sundsvall, Suécia, 9-15 jun 1991. [acesso em 2018 dez 8]. Disponível em: http://bvsms.saude.gov.br/bvs/publicacoes/declaracao_sundsvall.pdf .

4. Cohen SC. Habitação saudável como um caminho para a promoção da saúde [tese]. Rio de Janeiro: Escola Nacional de Saúde Pública, Fundação Oswaldo Cruz; 2004. 167 p.

5. Cohen SC. Reabilitação de favelas: Até que ponto a tecnologia empregada é apropriada? [dissertação]. Rio de Janeiro: Escola Nacional de Saúde Pública, Fundação Oswaldo Cruz; 1993. 376 p.

6. Rojas MC, Peréz CB, editores. Vivienda Saludable, de cara a RIO + 20. Washington: OMS; 2012.

7. Simas MC, Cardoso TAO. Biossegurança e Arquitetura em Laboratórios de Saúde Pública. Rev Pós. 2008; 15(24):108-24.

8. World Health Organization. Housing: implications for health. Report of a WHO Consultation, Geneva, 9-15 June 1987. Geneva: WHO; 1987. [acesso em 2018 dez 10]. Disponível em: https://apps.who.int/iris/handle/10665/59443.

9. Organización Mundial de la Salud. Organización Panamericana de la Salud. Documento de Posición OPS sobre Políticas de Salud en la Vivienda, 1999. Washington: OMS; 1999. [acesso em 2018 dez 8]. Disponível em: http://www.bvsde.paho.org/bvsasv/e/iniciativa/ posicion/posicion.html.

10. Almeida ABS, Albuquerque MBM. Biossegurança: um enfoque histórico através da história oral. História, Ciências, Saúde-Manguinhos 2000; 7(1):171-84.

11. Simas CM, Cardoso TAO. Arquitetura e Biossegurança. In: Teixeira P, Valle S, editores. Biossegurança: uma visão multidisciplinar. 2. ed. Rio de Janeiro: Fiocruz; 2010. p. 75-110.

12. Cohen SC, Kligerman DC, Barcelos MRB. Espaços saudáveis e sustentáveis, biossegurança e resíduos. Perspectivas e controvérsias. Rev Bras Promoção da Saúde 2011; 24(3):274-83.

13. Oppermann CM. Manual de biossegurança para serviços de saúde. Porto Alegre: PMPA; 2003.

14. Carvalho APA, Tavares I. Modulação no projeto arquitetônico de estabelecimentos assistenciais de saúde: o caso dos hospitais Sarah. In: Anais do 30 Fórum de Tecnologia Aplicada à Saúde; 2002. Salvador: Universidade Federal da Bahia, Multgraf, 2002. [acesso em 2018 dez 10]. Disponível em: http://bvsms.saude. gov.br/bvs/publicacoes/modulacao_hospitais_sarah. pdf.

15. Câmara Brasileira da Indústria da Construção. Desempenho de edificações habitacionais: guia orientativo para atendimento à norma ABNT NBR 15575/2013. Fortaleza: Gadioli Cipolla Comunicação; 2013.

16. Associação Brasileiras de Normas Técnicas. NBR 15575-1: edificações habitacionais - desempenho parte 1: requisitos gerais. Rio de Janeiro: ABNT; 2013.

17. Associação Brasileiras de Normas Técnicas. NBR 10152: acústica- níveis de pressão sonora em ambientes internos a edificações. Rio de Janeiro: ABNT; 2017. 
18. Brasil. Ministério do Trabalho e Emprego. Portaria $n^{\circ} 876$, de 24/10/2018. Altera a Norma Regulamentadora NR 17. Ergonomia. Diário Oficial da União. 25 Out 2018. [acesso $12 \mathrm{dez} 2018$ ]. Disponível em: https://enit.trabalho.gov.br/portal/images/Arquivos_ SST/SST_NR/NR-17.pdf.
19. McPartland JF, McPartland BJ. Handbook of practical electrical design. 3th ed. New York: McGraw-Hill; 1999.

Recebido em 15/04/2019

Aprovado em 05/09/2019

Conflito de interesses: inexistente

Suporte financeiro: não houve 